ground. In particular, it is to be remembered that to the Greeks geometry was not a professional or technical craft, but "a divine service, pursued by the select minds who could face the shadowy world of abstract ideas".

The pattern of Greek geometry has a three-fold basis: definitions, axioms, postulates. Definitions are intended to tell us what we are talking about; axioms give the fundamental and general basis of philosophical language; postulates, which ask for certain propositions to be granted, are assumptions special to geometry. The distinction between axioms and postulates was clear to the Greeks, who properly based the theory of parallels on a postulate rather than on an axiom, but later workers confused the issue: Prof. Lanczos considers that Kant's philosophy is partly defective because ho placed axioms and postulates on the same footing. The present view of mathematics as a language and of deduction as a game with symbols again implies a three-fold basis of undefined elements, definitions and rules. The difference, according to Lanczos, is chiefly one of emphasis ; to the Greeks, mathematics was an abstract language describing real things, to us mathematics is a language which need not have a physical meaning. Only if a correspondence can be set up between mathematical words and physical objects does a physical meaning emerge.

In dealing with limits, Prof. Lanczos notes that in the theory of irrationals due to the great Eudoxus, the method of exhaustion uses sequences of inequalities and avoids infinitesimals and equations involving infinitesimals. The dangers of the concepts of Newton and Leibniz, so caustically exposed by Berkeley, do not arise. The Greek method, when allowance is made for the difference between their geometrical language and our algebraic language, is precisely that recovered in the early nineteenth century by Cauchy and Gauss, and developed during that century by Dedekind, Weierstrass and many others. The subtlety of the Greek genius is particularly well shown by the observation, attributed to Archimedes, that a hitherto undetected postulate is required in the method of exhaustion, namely, that if $\varepsilon$ is any positive number, an integer $n$ can be found such that $n \varepsilon>1$. It is, of course, now a commonplace that geometries can be constructed in which the Euclidean postulates hold, but in which the Archimedean postulate is not fulfilled.

Prof. Lanczos's conclusion is that contemporary mathematics adds nothing essentially new to the high standards of Greek rigour.

\section{FOOD INVESTIGATION, 1956}

$\mathrm{T}$

HE research with which the Food Investigation Board is concerned lies between primary production on one hand and nutrition on the other ; it includes, therefore, studies on the biological structure of raw foodstuffs and the changes that occur during storage, preservation, processing and cooking. The Board recognizes two types of objectives in its investigations, the first being knowledge of the physical and chemical properties of various types of foodstuffs, while the second is of short range and is concerned with the solution of specific practical problems. This dual approach is well illustrated in
"Food Investigation 1956"*, which contains the reports of the Food Investigation Board and of the director of the Food Investigation Organization.

In the former the importance of close collaboration between research stations and the industries concerned with implementing the results of the research is emphasized. With this end in view, the setting up of a meat research laboratory in close association with an abattoir is strongly recommended. The Board is satisfied that a proper balance is maintained within the Organization between fundamental and applied work for the attainment of ultimate practical objectives.

The Director's report gives details of work performed during the year in the various stations of the Organization; on fish and fish products at the Torry Research Station and Humber laboratory, on fruit, vegetables and plant products at the Ditton and Covent Garden laboratiories, and at the Low Temperature Research Station in Cambridge on meat and meat products, eggs and poultry, as well as biochemistry and biophysies.

Work at Torry has continued on the effects of preservative ice containing chlortetracycline (aureomycin) on the keeping quality of fish. Full-scale trials were conducted on the Station's research vessel Sir William Hardy, and it was concluded that the presence of 5 p.p.m. of the antibiotic in the ice extended the storage life of fish in ice by seven to ten days. Food regulations in Britain at present do not permit such additions to ice, and considerable work is needed before this practice can indeed be shown to be harmless. Work has also been concerned with the cleanliness of fish boxes, which has been shown to affect the keeping quality of fish. Since cleaning and sterilizing of wooden boxes are difficult problems, trials with a non-returnable fish box of moulded resin-impregnated paper pulp have been continued. Basic investigations include studies on the proteins, lipids and extractives of fish flesh, and on the chemicals responsible for the development of brown discolorations during the dehydration of fish. The well-known sugar-amino-acid reaction is not, apparently, the only factor concerned. Other basic work has been on some of the physical factors that affect the deposition of smoke during smoke curing. The bacteriology section has continued its investigations on marine bacteria, and a type culture collection is maintained that is used by workers throughout the world.

In the Meat and Meat Products Division at the Low Temperature Research Station and the Smithfield laboratory, work has proceeded on the improvement of the quality of frozen beef and on the problem of carcass wastage, that is, the loss of weight of animals that takes place prior to slaughter. Basic work included a detailed study of normal rigor in animals and of the distribution of dipeptides within the muscles of various species.

A feature of the work of the General Biochemistry and Biophysics Division has been a study of the preservation of foods with ionizing radiations. This work, begun on a small scale in 1949, was resumed in 1955 and is now particularly directed to the treatment of meat. One of the main problems is that a dose of radiation sufficient to sterilize a foodstuff

* Department of Scientific and Industrial Research. Food Investigation 1956. Report of the Food Investigation Board with the Repor of the Director of the Food Investigation Organization. Pp. 68. (London: H.M. Stationery Office, 1957.) 3s. 6d. net. 


\section{№. 4591 October 26, $1957 \quad$ N A T U R E}

usually produces an unpleasant odour and flavour. Consequently radiation 'pasteurization', in which considerably lower dosages are required, seems to show more promise; the product, although not sterile, has an enhanced storage life at low temperatures.

Studies in the Fruit, Vegetables and Plant Products Division include work on nitrogen metabolism in fruit trees, on the organic acids in apples, strawberries and cherries, and on the respiration of apple tissue slices. Of a more immediately practical nature has been the work on the storage and transport of fruits and vegetables. Considerable success has been achieved with the transport of precooled strawberries in insulated containers with solid carbon dioxide suspended at roof-level, and in the use of nonyl alcohol as a sprout suppressant for potatoes. The Covent Garden laboratory has now increased its collection of coloured slides of disorders and diseases of fruits and vegetables to more than three hundred and fifty.

The volume concludes with details of the Food Investigation staff and a list of the ninety-four publications by members of the staff during the year. There is a complete index, and the report can be thoroughly recommended as a compact record of the results obtained and as a guide to the directions in which work is progressing in food research in Britain to-day.

P. L. Pellett

\section{THE MELLON INSTITUTE REPORT FOR 1956}

$\mathrm{T}$

HE annual report of the chairman, M. B. Ridgway, to the Board of Trustees of the Mellon Institute for the year ended February 28, 1957, in which the Institute expended $5,187,353$ dollars on fundamental and applied research, is entitled "Advantages from Research in Mellon Institute"*. Before describing the activities of the various research departments and fellowships, the roport outlines the respective advantages of basic and applied researeh, following the 'Trustees' decision this year to cultivate extensive fundamental research, particularly on major problems of far-reaching importance to chemistry and allied sciences. Fifty-five members were employed in the six research departments, and 507 fellows and assistants were working in the forty-five multiple and twenty-four individual fellowships in operation during the year, while the servicing staff numbered 214. Of these fellowships, eight had been in operation for thirty-five years or more, six for twenty-five years, twelve for twenty, nine for fifteen and three for ten years.

In the Department of Research in Chemical Physics a new mounting device for carbon replicas, developed for orienting surface structures visible under the light microscope so that electron micrographs may be obtained, has been used for studying the complicated structure of cleavage surfaces in the amethyst. A reference intensity scale for visual comparison of the line intensity on a photographic emulsion has been developed for semi-quantitative spectrochemical analysis. Spectral evidence was

* Advantages from Research in Mellon Institute, 1956-1957. Pp. * Advantages from Research in Melon Institute, 1956-1957 Pp.
vi +54. (Annual Report Series, No. 44.) (Pittsburgh, Pa.: Mellon vi +54 . (Annual
Institute, 1957 .) obtained of tautomerism in diazo ketones and an X-ray diffraction method was developed for determining total crystallinity in elastomers which undergo preferential molecular orientation before crystallization.

In the Department of Research in Physical Chemistry the use of nuclear magnetic resonance spectra of adsorbed particles on silica and other absorbents is being investigated. Various organic liquids were separated by thermal diffusion and in the study of packed columns collulose was substituted for glass-wool packing and further studies were made in the design and operation of a thermal diffusion column with a top reservoir. Work on the determination of branching in diene polymers was started.

In the Department of Instrumentation work continued on the evaluation and development of analytical balances and a new technique has been devised which involves modified arresting, mechanical handling of the weighed object and a new case design so that the whole operation can be performed automatically while a printed record is obtained. Rapid weighing at high temperatures is also being explored, while the Department of Applied Mathematics has worked at a series solution for large deflexions in simply supported disks under uniform loading. An investigation of combustion methods at high temperatures for the macrodetermination of carbon, hydrogen, sulphur and halogens in organic or metalloorganic compounds was initiated in the Department of Analytical Chemistry, where a procedure was devised for microdetermination of small amounts of residual carbon on inorganic catalysts, and the fundamental study of Ferrobacillus ferroxidans, the chemosynthetic autotrophic bacterium isolated from bituminous coal mines, was continued. The Department of Radiation Research, created in September 1956, is seeking to apply the radio-iodine scavenger technique to determine the nature of the free radicals produced in the radiolysis of organic materials.

Among the programmes of the Institute's continued fellowships may be mentioned a completed two-year investigation of the pulmonary effects of synthetic silicate materials, and investigations of the relation between the products of laboratory fermenta. tions of vegetable matter and organic substances found in natural streams, using the carbon-filter technique, which indicate that the phenolic material consists of highly substituted single phenyl rings. Besides the preparation of anticarcinogenic agents related to bifunctional molecules, such as the nitromustards, and substances related to azaserine, the antimetabolites of $p$-hydroxybenzoic acid have been examined in a search for agents effective against typhoid fever, malaria and tuberculosis. Drugs effective against schistosomiasis and virus diseases have also been sought. Under the Amine Fellowship new or improved processes for the preparation and manufacture of more than fifty medicinals have been studied intensively, and improved methods have been devised for administration or pharmaceutical use of established drugs, including a granular form of aminophylline, while a 1 per cent aqueous solution of iodine, containing triethanolamine hydriodide as solubilizing agent, was found to be an efficient antiseptic and germicide with comparatively low irritant action on tissues.

The Multiple Fellowship on Power Rectifiers is placing increasing emphasis on the preparation and purification of silicon with a view of developing an 